\title{
Identification of biomarkers for childhood obesity based on expressional correlation and functional similarity
}

\author{
ZHENG-LUN ZHU, QIU-MENG YANG, CHEN LI, JUN CHEN, MIN XIANG, \\ MING-MIN CHEN, MIN YAN and ZHENG-GANG ZHU
}

\begin{abstract}
Department of General Surgery, The Shanghai Institute of Digestive Surgery, Ruijin Hospital, Shanghai Jiaotong University School of Medicine, Shanghai 200025, P.R. China
\end{abstract}

Received April 13, 2015; Accepted February 11, 2016

DOI: $10.3892 / \mathrm{mmr} .2017 .7913$

\begin{abstract}
The aim of the current study was to identify potential biomarkers of childhood obesity, and investigate molecular mechanisms and candidate agents in order to improve therapeutic strategies for childhood obesity. The GSE9624 gene expression profile was downloaded from the Gene Expression Omnibus database. The differentially expressed genes (DEGs) in omental adipose tissues were analyzed with limma package by comparing samples from obese and normal control children. Two-way hierarchical clustering was applied using the pheatmap package. The co-expression (CE) analysis was performed using online CoExpress software. Subsequent to functional classification via the GOSim package, the gene network enriched by DEGs was visualized using the Cytoscape package. The codon usage bias of the DEGs was then examined using the CAI program from the European Molecular Biology Open Software Suite. In total, 583 DEGs (273 upregulated genes and 310 downregulated genes) were observed in the omental adipose tissues between samples from obese and normal control children. Hierarchical clustering identified a significant difference between samples from obese and normal control children. Subsequent to CE analysis, 130 DEGs, which were classified into 4 clusters, were selected. The following 3 upregulated and 2 downregulated genes were identified to be significant: Upregulated genes, microtubule-associated protein tau (MAPT), destrin (actin depolymerizing factor) $(D S T N)$ and spectrin, $\beta$, non-erythrocytic 1 (SPTBN1); downregulated genes, Rho/Rac guanine nucleotide exchange factor 2 (ARHGEF2) and spindle and kinetochore associated
\end{abstract}

Correspondence to: Dr Min Yan or Dr Zheng-Gang Zhu, Department of General Surgery, The Shanghai Institute of Digestive Surgery, Ruijin Hospital, Shanghai Jiaotong University School of Medicine, 197 Ruijin Road II, Shanghai 200025, P.R. China

E-mail: minyanmym@163.com

E-mail: zhenggangzhuzgz@163.com

Key words: childhood obesity, co-expression analysis, differentially expressed genes, functional classification, gene network complex subunit 1 (SKAl). The top 3 amino acids were identified to be glycine, leucine and serine with a high bias. The DEGs MAPT, DSTN, SPTBN1, ARHGEF2 and SKA1 are suggested to be candidate biomarkers for childhood obesity.

\section{Introduction}

Childhood obesity is a prevalent disease worldwide (1)and has been recognized as a serious public health concern due to its increasing morbidity in addition to adverse health effects (2). Compared with normal-weight children, obese children have an increased probability of obesity in adulthood (3), which may lead to hypertension, diabetes, dyslipidemia, chronic heart disease and other disorders (4). In addition, the prevalence of depression in obese children is greater than those of normal-weight children (5).

Obesity in children is a multifactorial disease, to which numerous genetic factors contribute (6). Previous genetic studies have identified that the mutation in melanocortin-4 receptor $(M C 4 R)$ is associated with childhood obesity through binding with $\alpha$-melanocyte-stimulating hormone ( $\alpha-\mathrm{MSH})$. It has been identified that $\alpha$-MSH could inhibit feeding, thus leading to an increasing risk of obesity (7-10). A missense amino acid substitution $(R 236 G)$ has been reported to contribute to an inherited susceptibility to obesity. The $R 236 G$ mutation contributes to an aberrant fusion protein, which is capable of interfering with central melanocortin signaling and appears to increase the risk of early-onset obesity (11-13). The fat mass and obesity associated gene has been recognized as another gene relevant to childhood obesity by influencing appetite and body composition $(14,15)$. However, the effective approaches of preventing obesity development in children remain limited and further studies of the molecular mechanisms are required.

The aim of the present study was to identify potential biomarkers of childhood obesity. Furthermore, the current study aimed to elucidate the molecular mechanism for the therapy of childhood obesity. The significant differentially expressed genes (DEGs) in omental adipose tissues were screened by comparison of samples between obese and normal-weight children with two-way hierarchical clustering, co-expression (CE) analysis and gene network construction. The notable amino acids were identified by measuring of codon usage bias. 


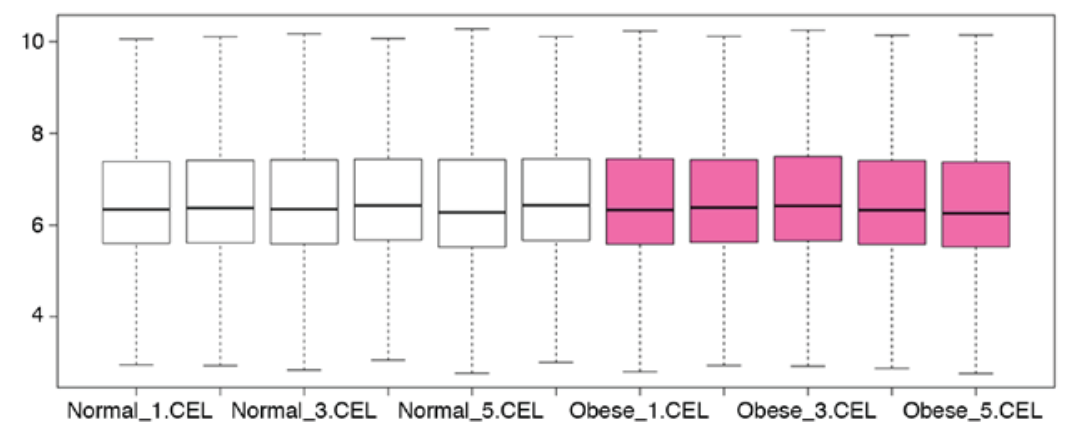

Figure 1. Boxplot graph of chip data distribution. The data were normalized and available for differentially expressed gene selection. The pink and white boxes represent samples of omental adipose tissues in obese and normal children, respectively. The x-axis represents samples; the $y$-axis represents gene expression values. The black horizontal line in each box represents the median value of the chip data, and the median indicates the gene expression value subsequent to normalization.

\section{Materials and methods}

Source of data. The microarray expression profile of GSE9624 (http://www.ncbi.nlm.nih.gov/geo/query/acc. cgi?acc=GSE9624) was extracted from the Gene Expression Omnibus database, based on the Affymetrix Human Genome U133 Plus 2.0 Array GPL570 (HG-U133_Plus_2). The data used was originally from 11 samples of omental adipose tissues, with 5 from obese children and 6 from normal-weight children.

Data preprocessing and DEGs analysis. The probe-level data in the CEL files were converted into expression measures using the Affy package (version 1.48.0) (16) with R software (https://www.r-project.org/). Missing data were inputted and data normalization was performed using quartile normalization (17). A boxplot graph was produced to present the chip data distribution and the median values. When the median values were consistent subsequent to normalization, the chip data were used for DEGs analysis.

The omental adipose tissues of normal-weight children were considered as the controls. DEGs in omental adipose tissues between obese children samples and normal controls were identified by the limma package (version 3.26.8) (https://bioconductor.org/packages/release/bioc/html/limma. html) (18). The P-values and log fold change (logFC) were calculated. $\mathrm{P}<0.01$ and $\log \mathrm{FCl}>1$ were considered as the cut-off criteria.

Hierarchical clustering of DEGs. Two-way hierarchical clustering was applied using the pheatmap package in $\mathrm{R}$ language (version 1.0.8) (https://cran.r-project.org/web/packages/pheat map/index.html) (19). Subsequently, the heat map of the DEGs was generated. The clustering was performed using the Euclidean distance and Ward's method (20).

CEanalysis ofDEGs. TheCEanalysis wasperformedusing online CoExpress software (http://www.bioinformatics.lu/CoExpress/). To identify CE DEGs, the correlation coefficient of each gene pair was calculated using the Pearson's correlation coefficient (21). The correlation coefficient ranged from -1 to +1 , '-' represented a negative correlation and ' + ' represented a positive correlation. When $\mathrm{CE}<0.95$, the gene pairs were cut off. Subsequently, the $\mathrm{CE}$ gene network was constructed by connecting the CE genes with straight lines.
Gene network construction. The functional similarity of DEGs was calculated using GOSim package (version 1.8.0) (https://www.bioconductor. org/packages/release/bioc/html/GOSim.html) (22), which functions based on various information theoretic similarity concepts for gene ontology $(\mathrm{GO})$ terms. $\mathrm{P}<0.05$ was used as the cut-off criterion.

Following functional classification, the gene network enriched by the screened DEGs was constructed. The Cytoscape package (version 3.2.1) (http://www.cytoscape.org/) was applied for the network visualization (23).

Measures of codon usage bias. It has been previously identified that there are large differences in codon usage bias among genes with different functions (24). The program of codon usage analysis has been previously used for analyzing codon and amino acid usage patterns (25). In the current study, the codon usage bias of the DEGs in each cluster was examined using the codon adaptation index (CAI) value, which was calculated with the CAI program from the European Molecular Biology Open Software Suite (version 6.5.0) (http://emboss.sourceforge. net/index.html) (26). CAI values between 0 and 1 indicated a positive correlation between the codon usage bias and the CAI value.

\section{Results}

DEGs analysis. The boxplot graph demonstrated that the chip data had been normalized and were available for DEGs selection (Fig. 1).

Based on the cut-off criteria of $\mathrm{P}<0.01$ and $\log \mathrm{FCl}>1$, 583 DEGs were identified in omental adipose tissues between the samples from obese children and those of normal-weight controls, including 310 upregulated genes and 273 downregulated genes.

Hierarchical clustering of DEGs. The heat map of DEGs (Fig. 2) indicated a marked difference in the DEGs of omental adipose tissues between the samples from obese children and those of normal-weight controls, observed by the clear color difference.

CE analysis of DEGs. A total of 130 DEGs were selected using the cut-off criterion of $\mathrm{CE}>0.95$. The CE network of those DEGs is presented in Fig. 3. 


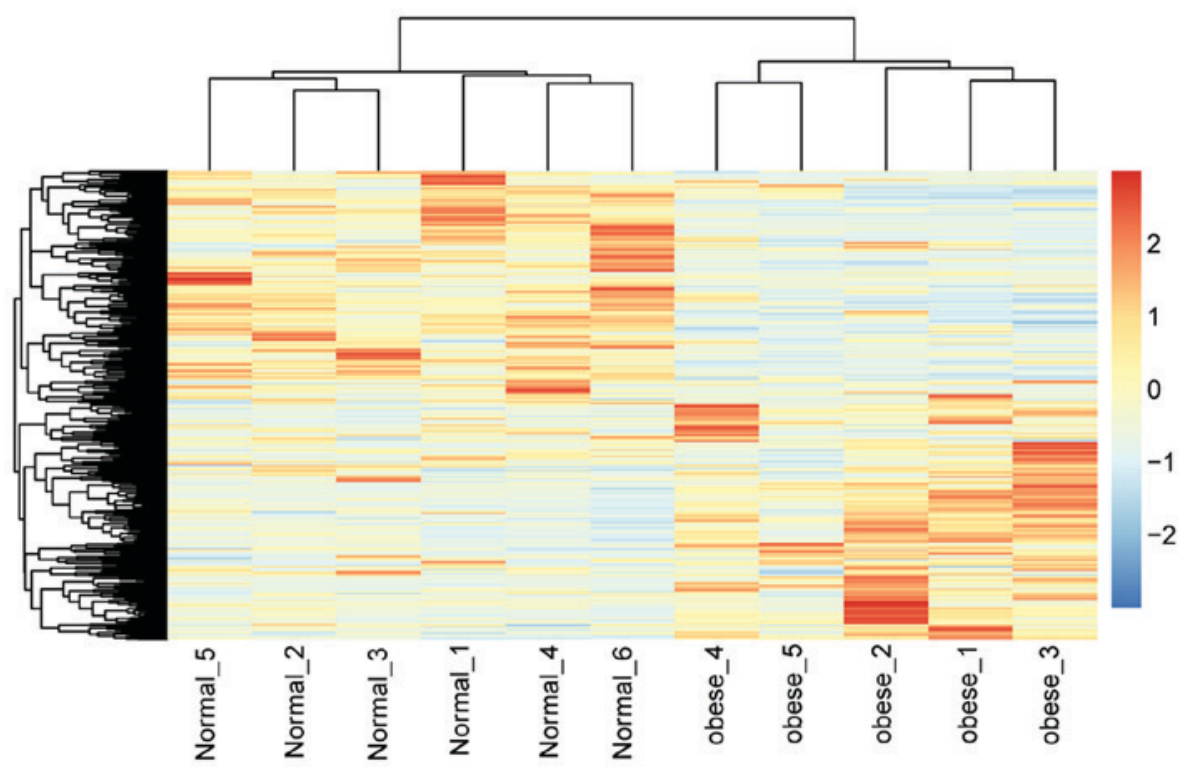

Figure 2. Heat map of differentially expressed genes. Red indicates high expression and blue indicates low expression. The color change from blue to red indicates movement from low to high levels of expression.

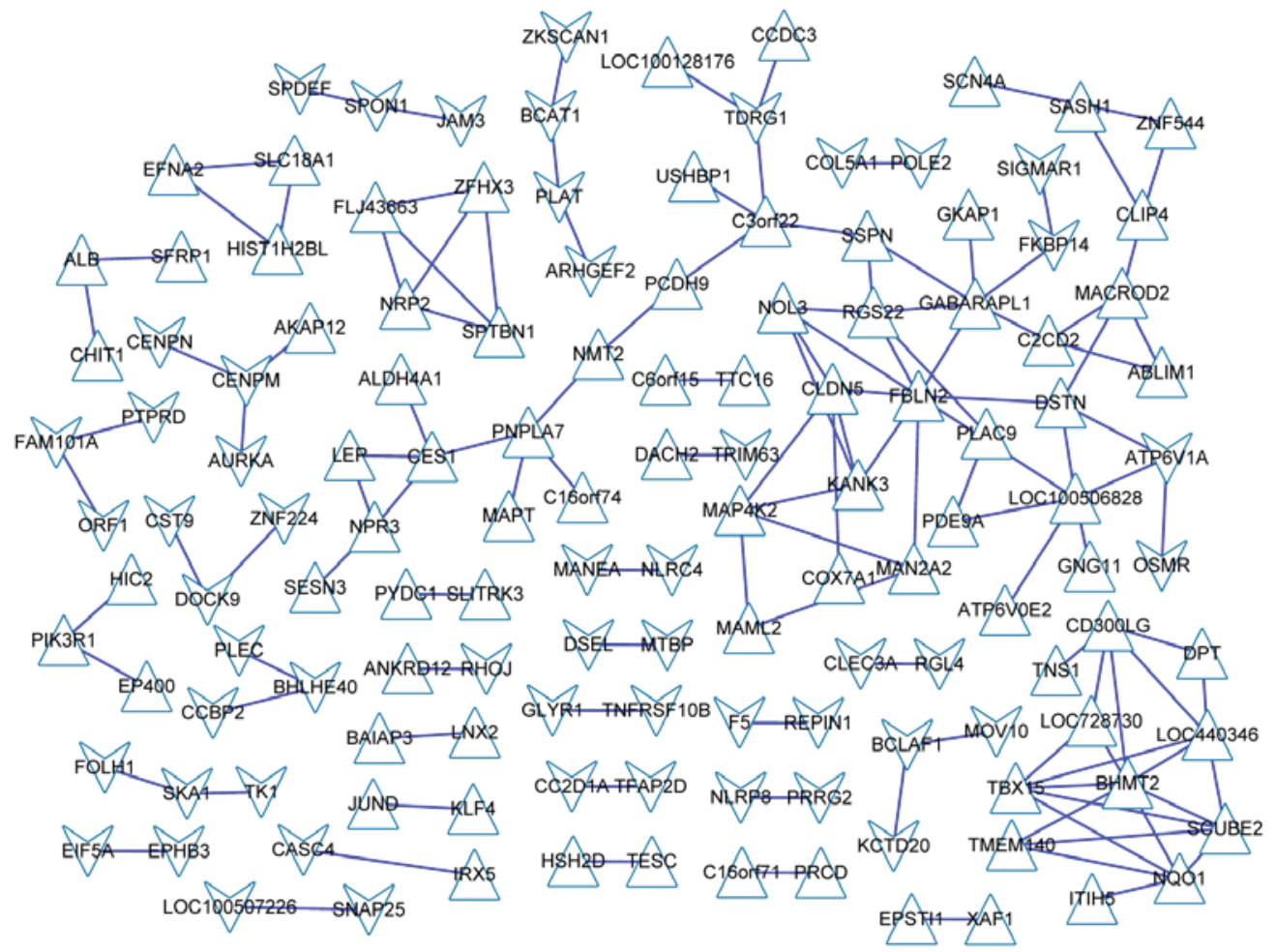

Figure 3. Co-expression network of the differentially expressed genes. The downward and upward triangles refer to down- and upregulated genes, respectively. The edges represent the interactions.

Gene network construction. Functional classification of the 130 DEGs was performed. According to the GO functional nodes of these DEGs, they were classified into 4 clusters (summarized in Table I).

The gene network of the DEGs with similarities of expression and function is presented in Fig. 4. The gene network included 38 nodes, 34 DEGs and 35 edges. There were 3 significantly upregulated genes [microtubule-associated protein tau $(M A P T)$, destrin (actin depolymerizing factor) $(D S T N)$ and spectrin, $\beta$, non-erythrocytic 1 (SPTBN1)] and 2 significantly downregulated genes [Rho/Rac guanine nucleotide exchange factor 2 (ARHGEF2) and spindle and kinetochore associated complex subunit $1(S K A l)]$.

Codon usage bias. The CAI values of the DEGs in the 4 clusters were 0.724 (cluster 1), 0.687 (cluster 2), 0.712 (cluster 3) and 0.705 (cluster 4), indicating a significant codon usage bias. To confirm the codon usage bias, amino acids translated by the 
Table I. Functional classification of correlated differentially expressed genes.

\begin{tabular}{|c|c|c|c|}
\hline Cluster name & Genes & Enrichment P-value & Biological function \\
\hline \multirow[t]{4}{*}{$\mathrm{C} 1(\mathrm{BP})$} & ARHGEF2, MAPT, SPTBN1, SKA1, DSTN & 0.0154 & $\begin{array}{l}\text { GO:0051493 regulation of cytoskeleton } \\
\text { organization }\end{array}$ \\
\hline & ARHGEF2, MAPT, SKAl & 0.0199 & $\begin{array}{l}\text { GO:0031110 regulation of microtubule } \\
\text { polymerization or depolymerization }\end{array}$ \\
\hline & ARHGEF2, MAPT, SKA1 & 0.0350 & $\begin{array}{l}\text { GO:0070507 regulation of microtubule } \\
\text { cytoskeleton organization }\end{array}$ \\
\hline & $A R H G E F 2, M A P T, S K A 1$ & 0.0464 & $\begin{array}{l}\text { GO:0032886 regulation of microtubule- } \\
\text { based process }\end{array}$ \\
\hline \multirow[t]{3}{*}{$\mathrm{C} 2(\mathrm{BP})$} & ARHGEF2, MAPT, EIF5A, SPTBN1, DSTN & 0.0004 & $\begin{array}{l}\text { GO:0043244 regulation of protein } \\
\text { complex disassembly }\end{array}$ \\
\hline & ARHGEF2, MAPT, SPTBN1, SKA1, DSTN & 0.0154 & $\begin{array}{l}\text { GO:0051493 regulation of cytoskeleton } \\
\text { organization }\end{array}$ \\
\hline & $A R H G E F 2, M A P T, S P T B N 1$ & 0.0335 & $\begin{array}{l}\text { GO:0043242 negative regulation of } \\
\text { protein complex disassembly }\end{array}$ \\
\hline \multirow[t]{4}{*}{$\mathrm{C} 3(\mathrm{BP})$} & NRP2, LEP , SLITRK3, IRX5, & & \\
\hline & EFNA2, EPHB3, SNAP25 & 0.0320 & GO:0048666 neuron development \\
\hline & NRP2, SLITRK3, EFNA2, & & \\
\hline & EPHB3, SNAP25 & 0.0469 & GO:0007409 axonogenesis \\
\hline \multirow[t]{5}{*}{$\mathrm{C} 4(\mathrm{CC})$} & CENPN, CENPM, SKAl & 0.0064 & $\begin{array}{l}\text { GO:0000777 condensed chromosome } \\
\text { kinetochore }\end{array}$ \\
\hline & CENPN, CENPM, SKA1 & 0.0080 & $\begin{array}{l}\text { GO:0000779 condensed chromosome, } \\
\text { centromeric region }\end{array}$ \\
\hline & CENPN, CENPM, SKAl & 0.0104 & GO:0000776 kinetochore \\
\hline & CENPN, CENPM, SKAl & 0.0221 & $\begin{array}{l}\text { GO:0000775 chromosome, centromeric } \\
\text { region }\end{array}$ \\
\hline & CENPN, CENPM, SKAl & 0.0234 & GO:0000793 condensed chromosome \\
\hline
\end{tabular}

BP, biological process; GO, gene ontology; C1-4, cluster 1-4; CC, cellular component; ARHGEF, 2 Rho/Rac guanine nucleotide exchange factor 2; MAPT, microtubule-associated protein tau; SPTBN1, spectrin, $\beta$, non-erythrocytic 1; SKA1, spindle and kinetochore associated complex subunit 1; DSTN, destrin (actin depolymerizing factor); EIF5A, eukaryotic translation initiation factor 5A-1; NRP2, neuropilin 2; LEP, leptin; SLITRK3, SLIT and NTRK-like family member 3; IRX5, iroquois homeobox 5; EFNA2, ephrin-A2; EPHB3, ephrin type-B receptor 3; SNAP25, synaptosomal-associated protein 25; CENPN, centromere protein N; CENPM, centromere protein M.

codon in each sequence were summarized in Table II. The top 3 amino acids were glycine, leucine and serine, which exhibited a high bias.

\section{Discussion}

Childhood obesity is a multisystem disease with potentially life-threatening consequences (27). In spite of numerous genetic studies aiming to elucidate the pathogenesis of childhood obesity, the molecular mechanisms in the development and progression of this disease remain unclear. In the present study, 3 notably upregulated genes (MAPT, DSTN and SPTBNI) and 2 notable downregulated genes (ARHGEF2 and $S K A 1)$ were identified. Several functions, including microtubule polymerization or depolymerization, condensed chromosome kinetochore, regulation of cytoskeleton organization and regulation of microtubule cytoskeleton organization, were observed to be significantly enriched by these DEGs.

$S K A l$ is a protein-coding gene. The $S K A l$ complex is part of the conserved kinetochore-microtubule interface and directly associates with microtubules as part of oligomeric assemblies. It has been previously demonstrated to serve a critical role in interacting with dynamic microtubules at the outer kinetochore by depolymerizing microtubule ends (28). As presented in Table I and Fig. 4, SKAI was significantly enriched in regulation of microtubule polymerization or depolymerization. The depolymerizing microtubules attached by macromolecular kinetochores are necessary for the chromosome movements to ensure regular chromosome segregation (29,30). Notably, SKA1 was observed in the current study to also be enriched in cluster 4, which consisted of biological functions such as condensed chromosome kinetochore. Previous studies have identified that chromosomal (such as those on chromosome 11p14-p12 and chromosome 16p11.2) deletions may result in obesity (31-34). Therefore, it is suggested that $S K A 1$ may be associated with childhood obesity by depolymerizing microtubules and disturbing chromosome segregation.

An additional significantly downregulated gene identified in the present study is ARHGEF2. ARHGEF2 encodes guanine nucleotide exchange factor $\mathrm{H} 1$, which is a 
Table II. Codon usage of differential expression genes sequence in the 4 clusters.

AA Sum

Codon $\quad$ AA $\quad$ Cluster $1 \quad$ Cluster $2 \quad$ Cluster $3 \quad$ Cluster $4 \quad$\begin{tabular}{llll}
\cline { 3 - 3 } 1 & Cluster 2 & Cluster 3 & Cluster 4
\end{tabular}

\begin{tabular}{|c|c|c|c|c|c|c|c|c|c|}
\hline GCA & A & 194 & 26 & 695 & 190 & 712 & 148 & 2147 & 666 \\
\hline GCC & A & 253 & 40 & 641 & 210 & & & & \\
\hline GCG & A & 45 & 48 & 163 & 58 & & & & \\
\hline GCT & A & 220 & 34 & 648 & 208 & & & & \\
\hline TGC & $\mathrm{C}$ & 212 & 24 & 771 & 198 & 376 & 51 & 1579 & 427 \\
\hline TGT & $\mathrm{C}$ & 164 & 27 & 808 & 229 & & & & \\
\hline GAC & D & 128 & 20 & 469 & 117 & 270 & 40 & 1058 & 255 \\
\hline GAT & D & 142 & 20 & 589 & 138 & & & & \\
\hline GAA & $\mathrm{E}$ & 212 & 18 & 880 & 187 & 573 & 60 & 1731 & 436 \\
\hline GAG & $\mathrm{E}$ & 361 & 42 & 851 & 249 & & & & \\
\hline TTC & $\mathrm{F}$ & 203 & 46 & 857 & 216 & 531 & 108 & 2242 & 616 \\
\hline TTT & $\mathrm{F}$ & 328 & 62 & 1385 & 400 & & & & \\
\hline GGA & $\mathrm{G}$ & 281 & 46 & 842 & 198 & 1146 & 185 & 2907 & 765 \\
\hline GGC & $\mathrm{G}$ & 255 & 43 & 658 & 203 & & & & \\
\hline GGG & $\mathrm{G}$ & 387 & 62 & 825 & 180 & & & & \\
\hline GGT & $\mathrm{G}$ & 223 & 34 & 582 & 184 & & & & \\
\hline CAC & $\mathrm{H}$ & 179 & 22 & 693 & 200 & 341 & 43 & 1519 & 355 \\
\hline CAT & $\mathrm{H}$ & 162 & 21 & 826 & 155 & & & & \\
\hline ATA & I & 114 & 11 & 752 & 171 & 406 & 52 & 2302 & 528 \\
\hline ATC & I & 127 & 19 & 605 & 153 & & & & \\
\hline ATT & I & 165 & 22 & 945 & 204 & & & & \\
\hline AAA & $\mathrm{K}$ & 294 & 18 & 1478 & 406 & 491 & 44 & 2328 & 609 \\
\hline $\mathrm{AAG}$ & $\mathrm{K}$ & 197 & 26 & 850 & 203 & & & & \\
\hline CTA & $\mathrm{L}$ & 134 & 18 & 470 & 136 & 1322 & 212 & 4625 & 1282 \\
\hline CTC & $\mathrm{L}$ & 275 & 49 & 804 & 249 & & & & \\
\hline CTG & $\mathrm{L}$ & 372 & 42 & 958 & 288 & & & & \\
\hline СТT & $\mathrm{L}$ & 220 & 45 & 851 & 230 & & & & \\
\hline TTA & $\mathrm{L}$ & 135 & 21 & 778 & 173 & & & & \\
\hline TTG & $\mathrm{L}$ & 186 & 37 & 764 & 206 & & & & \\
\hline ATG & M & 165 & 22 & 776 & 183 & 165 & 22 & 776 & 183 \\
\hline $\mathrm{AAC}$ & $\mathrm{N}$ & 109 & 10 & 617 & 163 & 244 & 22 & 1550 & 384 \\
\hline AAT & $\mathrm{N}$ & 135 & 12 & 933 & 221 & & & & \\
\hline $\mathrm{CCA}$ & $\mathrm{P}$ & 273 & 35 & 880 & 214 & 1029 & 157 & 2750 & 682 \\
\hline $\mathrm{CCC}$ & $\mathrm{P}$ & 339 & 57 & 831 & 170 & & & & \\
\hline $\mathrm{CCG}$ & $\mathrm{P}$ & 86 & 17 & 213 & 69 & & & & \\
\hline $\mathrm{CCT}$ & $\mathrm{P}$ & 331 & 48 & 826 & 229 & & & & \\
\hline CAA & Q & 178 & 24 & 832 & 177 & 495 & 60 & 1815 & 448 \\
\hline CAG & Q & 317 & 36 & 983 & 271 & & & & \\
\hline AGA & $\mathrm{R}$ & 289 & 30 & 1020 & 228 & 846 & 137 & 2503 & 663 \\
\hline AGG & $\mathrm{R}$ & 337 & 41 & 843 & 233 & & & & \\
\hline CGA & $\mathrm{R}$ & 35 & 9 & 128 & 48 & & & & \\
\hline CGC & $\mathrm{R}$ & 64 & 16 & 143 & 58 & & & & \\
\hline CGG & $\mathrm{R}$ & 80 & 28 & 233 & 51 & & & & \\
\hline CGT & $\mathrm{R}$ & 41 & 13 & 136 & 45 & & & & \\
\hline $\mathrm{AGC}$ & $\mathrm{S}$ & 264 & 30 & 662 & 194 & 1235 & 182 & 3930 & 1118 \\
\hline AGT & $\mathrm{S}$ & 207 & 23 & 666 & 188 & & & & \\
\hline TCA & $\mathrm{S}$ & 191 & 31 & 795 & 227 & & & & \\
\hline TCC & $\mathrm{S}$ & 252 & 44 & 771 & 202 & & & & \\
\hline TCG & $\mathrm{S}$ & 47 & 12 & 126 & 40 & & & & \\
\hline TCT & $\mathrm{S}$ & 274 & 42 & 910 & 267 & & & & \\
\hline
\end{tabular}


Table II. Continued.

AA Sum

\begin{tabular}{lcrrrrrrrr}
\cline { 6 - 9 } Codon & AA & Cluster 1 & Cluster 2 & Cluster 3 & Cluster 4 & Cluster 1 & Cluster 2 & Cluster 3 & Cluster 4 \\
\hline ACA & T & 164 & 12 & 845 & 206 & 538 & 72 & 2187 & 587 \\
ACC & T & 197 & 25 & 564 & 134 & & & & \\
ACG & T & 33 & 10 & 131 & 54 & & & & \\
ACT & T & 144 & 25 & 647 & 193 & & & & \\
GTA & $\mathrm{V}$ & 124 & 13 & 435 & 136 & 642 & 112 & 2144 & \\
GTC & $\mathrm{V}$ & 136 & 24 & 433 & 126 & & & & \\
GTG & $\mathrm{V}$ & 246 & 39 & 680 & 212 & & & & \\
GTT & $\mathrm{V}$ & 136 & 36 & 596 & 160 & & & & \\
TGG & $\mathrm{W}$ & 331 & 42 & 945 & 233 & 331 & 42 & 945 & \\
TAC & $\mathrm{Y}$ & 95 & 11 & 397 & 132 & 179 & 24 & 1090 & \\
TAT & $\mathrm{Y}$ & 84 & 13 & 693 & 173 & & & & \\
TAA & $*$ & 108 & 9 & 819 & 214 & & & & \\
TAG & $*$ & 134 & 17 & 526 & 149 & & & & \\
TGA & $*$ & 208 & 22 & 827 & 206 & & &
\end{tabular}

Columns 3-6 indicate the number of codons of the differentially expressed genes in each cluster. The last column shows the number of AA encoded by different codons. *No corresponding amino acid. AA, amino acid; A, alanine; C, cysteine; D, aspartate; E, glutamate; F, phenylalanine; G, glycine; H, histidine; I, isoleucine; $\mathrm{K}$, lysine; L, leucine; M, methionine; N, asparagine; P, proline; Q, glutamine; R, arginine; S, serine; T, threonine; V, valine; W, tryptophan; Y, tyrosine.

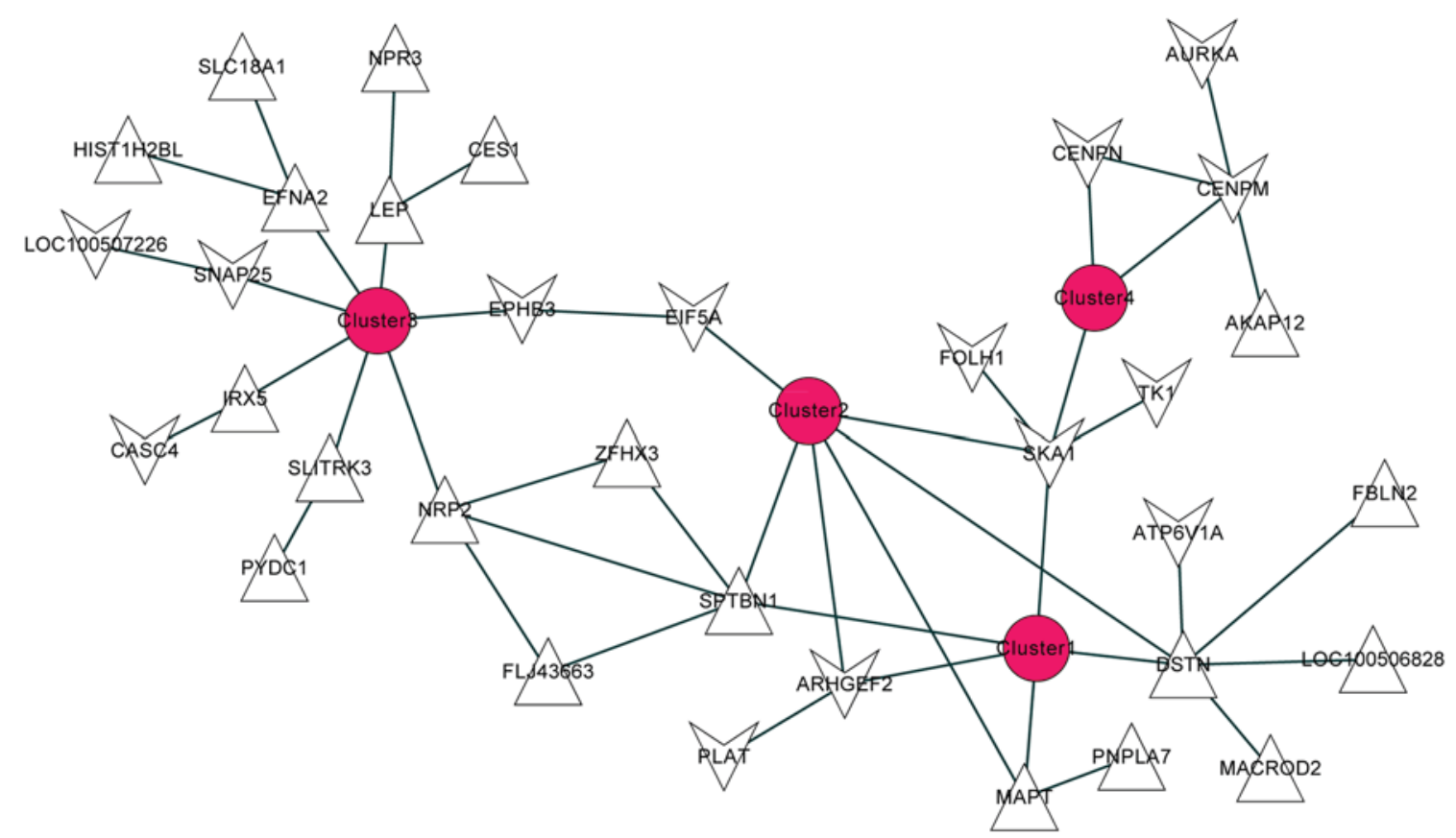

Figure 4. Gene network of differentially expressed genes with similarity of expression and function. The downward and upward triangles refer to down- and upregulated genes, respectively. The red circular nodes represent functional clusters. The edges represent the interactions.

microtubule-associated exchange factor $(35,36)$. ARHGEF2 activity is downregulated by interaction of its $\mathrm{C}$-terminus with microtubules (37). Rho GEF is associated with microtubules and becomes active upon microtubule depolymerization (38). Through functional analysis, ARHGEF 2 was observed to be significantly enriched in the regulation of microtubule polymerization or depolymerization. Hence, similar to that of
$S K A 1$, it is suggested that $A R H G E F 2$ may be a candidate gene in childhood obesity, acting via targeting the regulation of microtubule polymerization or depolymerization.

In the present study, MAPT was observed as a significantly upregulated gene. MAPT encodes the microtubule-associated protein (MAP) tau. MAP has been observed to serve an important role in the promotion of microtubule assembly in vitro (39). 
The results of the current study indicated that MAPT targeted regulation of microtubule cytoskeleton organization. Previous studies have demonstrated that disruption of microtubule assembly inhibited the translocation of the insulin responsive glucose transporter isoform (GLUT4) $(40,41)$. GLUT4 translocation promotes insulin to stimulate glucose uptake in adipose tissue, ultimately resulting in obesity (42). Thus, MAPT may serve a stimulative role in the development and progression of childhood obesity.

SPTBN1 is a member of the $\beta$-spectrin gene family (43). Spectrin is a protein functioning in actin cross-linking and the molecular scaffold. It connects the plasma membrane to the actin cytoskeleton and determines cytoskeleton organization including cell shape, arrangement of transmembrane proteins and organization of organelles (44). SPTBN1 was identified in the current study as a significantly upregulated gene, enriched in pathway of regulation of cytoskeleton organization. Cytoskeleton organization is a biological process involving various cellular components in adipose tissues. Fat deposition in mature fat cells and cell proliferation have been suggested to accelerate pre-adipocytes to differentiate into adipocytes, serving a role in the regulation of body weight (45). Thus, it is suggested that SPTBN1 may be a candidate gene for childhood obesity, acting via the regulation of cytoskeleton organization function.

$D S T N$ encodes for the protein destrin. Destrin is a $\mathrm{pH}$-independent protein, with the capacity to sever actin filaments (F-actin) (46). Destrin has been previously reported to serve a role in the reorganization of the actin cytoskeleton in response to stress and cell stimuli (47). In addition, destrin belongs to the actin-depolymerizing factor family, which mediates a $\mathrm{pH}$-sensitive destruction of actin filaments (48-51). Filament networks, such as peripheral actin filaments, have been identified to have a mechanical connection to various cytoskeletal structures (52). By reviewing the functional classifications and the gene network in the current study, it is suggested that DSTN participates in the regulation of cytoskeletal organization. Previously, organization of the actin cytoskeleton was suggested to be necessary for early adipocyte differentiation, resulting in hyperplasia of adipose tissues which is a critical event for the development of obesity $(53,54)$. This led to it being hypothesized that DSTN may be a biomarkers of childhood obesity.

However, there were limitations in the present study. The results obtained were web-based and were not verified by any biological experiments. In addition, the data downloaded were from a European database, it remains unclear whether these results would be consistent for children from other continents. Thus, further experimental studies based on the observations of the current study are required.

In conclusion, MAPT, DSTN,SPTBN1,ARHGEF 2 and SKAI may be candidate biomarkers of childhood obesity. Microtubule polymerization or depolymerization, condensed chromosome kinetochore, regulation of cytoskeleton organization and regulation of microtubule cytoskeleton organization may be important biological pathways in the progression of childhood obesity. The observations of the current study may have implications for the understanding of the molecular mechanisms, and identification of candidate therapeutic agents, for childhood obesity. However, further studies are required to confirm the preliminary observations outlined in the current study, with the aim of this information being used in a clinical setting.

\section{Acknowledgements}

The current study was supported by the Shanghai Universities Young Teachers Training Scheme (grant no. Zzjdyx12021).

\section{References}

1. Etelson D, Brand DA, Patrick PA and Shirali A: Childhood obesity: Do parents recognize this health risk? Obes Res 11: 1362-1368, 2003.

2. Dietz WH: Health consequences of obesity in youth: Childhood predictors of adult disease. Pediatrics 101: 518-525, 1998.

3. Dehghan M, Akhtar-Danesh N and Merchant AT: Childhood obesity, prevalence and prevention. Nutr J 4: 24, 2005.

4. Daniels SR: The consequences of childhood overweight and obesity. Future Child 16: 47-67, 2006.

5. French SA, Story M and Perry CL: Self-esteem and obesity in children and adolescents: A literature review. Obes Res 3: 479-490, 1995.

6. Han JC, Lawlor DA and Kimm SY: Childhood obesity. Lancet 375: 1737-1748, 2010.

7. Govaerts C, Srinivasan S, Shapiro A, Zhang S, Picard F, Clement K, Lubrano-Berthelier C and Vaisse C: Obesity-associated mutations in the melanocortin 4 receptor provide novel insights into its function. Peptides 26: 1909-1919, 2005.

8. Tao YX and Segaloff DL: Functional characterization of melanocortin-4 receptor mutations associated with childhood obesity. Endocrinology 144: 4544-4551, 2003.

9. Yeo GS, Farooqi IS, Aminian S, Halsall DJ, Stanhope RG and O'Rahilly S: A frameshift mutation in MC4R associated with dominantly inherited human obesity. Nat Gene 20: 111-112, 1998.

10. Miraglia Del Giudice E, Cirillo G, Nigro V, Santoro N, D'urso L, Raimondo P, Cozzolino D, Scafato D and Perrone L: Low frequency of melanocortin-4 receptor (MC4R) mutations in a Mediterranean population with early-onset obesity. Int J Obes Relat Metab Disord 26: 647-651, 2002.

11. Challis BG, Pritchard LE, Creemers JW, Delplanque J, Keogh JM, Luan J, Wareham NJ, Yeo GS, Bhattacharyya S, Froguel P, et al: A missense mutation disrupting a dibasic prohormone processing site in pro-opiomelanocortin (POMC) increases susceptibility to early-onset obesity through a novel molecular mechanism. Hum Mol Genet 11: 1997-2004, 2002.

12. Santoro N, Perrone L, Cirillo G, Raimondo P, Amato A, Coppola F, Santarpia M, D'Aniello A and Miraglia Del Giudice E: Weight loss in obese children carrying the proopiomelanocortin R236G variant. J Endocrinol Invest 29: 226-230, 2006.

13. Hung CN, Poon WT, Lee CY, Law CY and Chan AY: A case of early-onset obesity, hypocortisolism, and skin pigmentation problem due to a novel homozygous mutation in the proopiomelanocortin (POMC) gene in an Indian boy. J Pediatr Endocrinol Metab 25: 175-179, 2012.

14. Wardle J, Carnell S, Haworth CM, Farooqi IS, O'Rahilly S and Plomin R: Obesity associated genetic variation in FTO is associated with diminished satiety. J Clin Endocrinol Metab 93: 3640-3643, 2008.

15. Gulati P, Cheung MK, Antrobus R, Church CD, Harding HP Tung YC, Rimmington D, Ma M, Ron D, Lehner PJ, et al: Role for the obesity-related FTO gene in the cellular sensing of amino acids. Proc Natl Acad Sci USA 110: 2557-2562, 2013.

16. Liu WM, Mei R, Di X, Ryder TB, Hubbell E, Dee S, Webster TA, Harrington CA, Ho MH, Baid J, et al: Analysis of high density expression microarrays with signed-rank call algorithms. Bioinformatics 18: 1593-1599, 2002.

17. Smyth GK and Speed T: Normalization of cDNA microarray data. Methods 31: 265-273, 2003.

18. Smyth GK: Limma: Linear models for microarray data. In: Bioinformatics and Computational Biology Solutions Using R and Bioconductor. Gentleman R, Carey VJ, Huber W, Irizarry RA and Dudoit S (eds). Springer, New York, pp397-420, 2005.

19. Team RC (ed): R: A Language and Environment for Statistical Computing. R Foundation for Statistical Computing, Vienna, 2012.

20. Deza MM and Deza E (eds): Encyclopedia of Distances. 1st edition. Springer-Verlag, Berlin, 2009.

21. Obayashi T, Kinoshita K, Nakai K, Shibaoka M, Hayashi S, Saeki M, Shibata D, Saito K and Ohta H: ATTED-II: A database of co-expressed genes and cis elements for identifying co-regulated gene groups in Arabidopsis. Nucleic Acids Res 35 (Database Issue): D863-D869, 2007. 
22. Fröhlich H, Speer N, Poustka A and Beissbarth T: GOSim-an R-package for computation of information theoretic GO similarities between terms and gene products. BMC Bioinformatics 8: 166, 2007.

23. Smoot ME, Ono K, Ruscheinski J, Wang PL and Ideker T: Cytoscape 2.8: New features for data integration and network visualization. Bioinformatics 27: 431-432, 2011.

24. Liu Q, Dou S, Ji Z and Xue Q: Synonymous codon usage and gene function are strongly related in Oryza sativa. Bio Systems 80: 123-131, 2005.

25. McInerney JO: GCUA: General codon usage analysis. Bioinformatics 14: 372-373, 1998

26. Rice P,Longden I and Bleasby A: EMBOSS: The European molecular biology open software suite. Trends Genet 16: 276-277, 2000.

27. Ebbeling CB, Pawlak DB and Ludwig DS: Childhood obesity: Public-health crisis, common sense cure. Lancet 360: 473-482, 2002.

28. Welburn JP, Grishchuk EL, Backer CB, Wilson-Kubalek EM, Yates JR III and Cheeseman IM: The human kinetochore Ska1 complex facilitates microtubule depolymerization-coupled motility. Dev Cell 16: 374-385, 2009.

29. Welburn JP, Grishchuk EL, Backer CB, Wilson-Kubalek EM, Yates JR III and Cheeseman IM: The human kinetochore Skal complex facilitates microtubule depolymerization-coupled motility. Dev Cell 16: 374-385, 2009.

30. Schmidt JC, Arthanari H, Boeszoermenyi A, Dashkevich NM, Wilson-Kubalek EM, Monnier N, Markus M, Oberer M, Milligan RA, Bathe M, et al: The kinetochore-bound Ska1 complex tracks depolymerizing microtubules and binds to curved protofilaments. Dev Cell 23: 968-980, 2012.

31. Bochukova EG, Huang N, Keogh J, Henning E, Purmann C, Blaszczyk K, Saeed S, Hamilton-Shield J, Clayton-Smith J, O'Rahilly S, et al: Large, rare chromosomal deletions associated with severe early-onset obesity. Nature 463: 666-670, 2010.

32. Farooqi IS: Genetic and hereditary aspects of childhood obesity. Best Pract Res Clin Endocrinol Metab 19: 359-374, 2005.

33. Walters RG, Jacquemont S, Valsesia A, de Smith AJ, Martinet D, Andersson J,Falchi M, Chen F, Andrieux J, Lobbens S, et al: A new highly penetrant form of obesity due to deletions on chromosome 16p11.2. Nature 463: 671-675, 2010

34. Bachmann-Gagescu R, Mefford HC, Cowan C, Glew GM, Hing AV, Wallace S, Bader PI, Hamati A, Reitnauer PJ, Smith R, et al: Recurrent 200-kb deletions of 16p11. 2 that include the SH2B1 gene are associated with developmental delay and obesity. Genet Med 12: 641-647, 2010.

35. Siesser PF, Motolese M, Walker MP, Goldfarb D, Gewain K, Yan F, Kulikauskas RM, Chien AJ, Wordeman L and Major MB: FAM123A binds to microtubules and inhibits the guanine nucleotide exchange factor ARHGEF2 to decrease actomyosin contractility. Sci Signal 5: ra64, 2012

36. Brajenovic M, Joberty G, Küster B, Bouwmeester T and Drewes G: Comprehensive proteomic analysis of human Par protein complexes reveals an interconnected protein network. J Biol Chem 279: 12804-12811, 2004.

37. Poroyko V and Birukova A: ARHGEF2 (rho/rac guanine nucleotide exchange factor (GEF) 2). Atlas Genet Cytogenet Oncol Haematol 4: 58, 2007.

38. Conde $\mathrm{C}$ and Cáceres A: Microtubule assembly, organization and dynamics in axons and dendrites. Nat Rev Neurosci 10 319-332, 2009.

39. Kuznetsov SA, Rodionov VI, Gelfand VI and Rosenblat VA Microtubule-associated protein MAP1 promotes microtubule assembly in vitro. FEBS Lett 135: 241-244, 1981.
40. Emoto M, Langille SE and Czech MP: A role for kinesin in insulin-stimulated GLUT4 glucose transporter translocation in 3T3-L1 adipocytes. J Biol Chem 276: 10677-10682, 2001.

41. Patki V, Buxton J, Chawla A, Lifshitz L, Fogarty K, Carrington W, Tuft R and Corvera S: Insulin action on GLUT4 traffic visualized in single 3T3-11 adipocytes by using ultra-fast microscopy. Mol Biol Cell 12: 129-141, 2001.

42. Kanzaki M and Pessin JE: Insulin-stimulated GLUT4 translocation in adipocytes is dependent upon cortical actin remodeling. J Biol Chem 276: 42436-42444, 2001.

43. Hillen N, Mester G, Lemmel C, Weinzierl AO, Müller M, Wernet D, Hennenlotter J, Stenzl A, Rammensee HG and Stevanović S: Essential differences in ligand presentation and $\mathrm{T}$ cell epitope recognition among HLA molecules of the HLA-B44 supertype. Eur J Immunol 38: 2993-3003, 2008.

44. Guilherme R, Guimiot F, Tabet AC, Khung-Savatovsky S, Gauthier E, Nouchy M, Benzacken B, Verloes A, Oury JF, Delezoide AL and Aboura A: Abnormal muscle development of the diaphragm in a fetus with 2p14-p16 duplication. Am J Med Genet A 149A: 2892-2897, 2009.

45. Aksu S, Koczan D, Renne U, Thiesen HJ and Brockmann GA Differentially expressed genes in adipose tissues of high body weight-selected (obese) and unselected (lean) mouse lines. J Appl Genet 48: 133-143, 2007.

46. Moriyama K, Yonezawa N, Sakai H, Yahara I and Nishida E: Mutational analysis of an actin-binding site of cofilin and characterization of chimeric proteins between cofilin and destrin. J Biol Chem 267: 7240-7244, 1992.

47. Yahara I, Aizawa H, Moriyama K, Iida K, Yonezawa N, Nishida E, Hatanaka $\mathrm{H}$ and Inagaki F: A role of cofilin/destrin in reorganization of actin cytoskeleton in response to stresses and cell stimuli. Cell Struct Funct 21: 421-424, 1996.

48. Agrawal PB, Greenleaf RS, Tomczak KK, Lehtokari VL, Wallgren-Pettersson C, Wallefeld W, Laing NG, Darras BT, Maciver SK, Dormitzer PR and Beggs AH: Nemaline Myopathy with minicores caused by mutation of the CFL2 gene encoding the skeletal muscle actin-binding protein, cofilin-2. Am J Hum Genet 80: 162-167, 2007

49. Verdoni AM, Aoyama N, Ikeda A and Ikeda S: Effect of destrin mutations on the gene expression profile in vivo. Physiol Genomics 34: 9-21, 2008.

50. Maciver SK and Hussey PJ: The ADF/cofilin family: Actin-remodeling proteins. Genome Biol 3: 3007, 2002.

51. Hawkins M, Pope B, Maciver SK and Weeds AG: Human actin depolymerizing factor mediates a $\mathrm{pH}$-sensitive destruction of actin filaments. Biochemistry 32: 9985-9993, 1993.

52. Wiche G: Role of plectin in cytoskeleton organization and dynamics. J Cell Sci 111: 2477-2486, 1998

53. Kawaguchi N, Sundberg C, Kveiborg M, Moghadaszadeh B, Asmar M, Dietrich N, Thodeti CK, Nielsen FC, Möller P, Mercurio AM, et al: ADAM12 induces actin cytoskeleton and extracellular matrix reorganization during early adipocyte differentiation by regulating beta1 integrin function. J Cell Sci 116: 3893-3904, 2003.

54. Bost F, Aouadi M, Caron L and Binétruy B: The role of MAPKs in adipocyte differentiation and obesity. Biochimie 87: 51-56, 2005.

This work is licensed under a Creative Commons Attribution-NonCommercial-NoDerivatives 4.0 International (CC BY-NC-ND 4.0) License. 